Revista Española de Antropología Americana ISSN: 0556-6533

http://dx.doi.org/10.5209/reaa.70398

\title{
Hipertexto, multivocalidad y multimodalidad para una etnografía sobre los medios de comunicación: la web MEDIOS INDÍGENAS
}

\author{
Gemma Orobitg ${ }^{1}$ y Roger Canals ${ }^{2}$
}

Recibido: 2 de julio de 2020 / Aceptado: 15 de agosto de 2020

Resumen. En este texto reflexionamos sobre la etnografía hipertextual y transmedia en términos metodológicos, éticos y teóricos. Nuestro análisis gira alrededor de la web MEDIOS INDÍGENAS que es parte de un proyecto de investigación colectivo y comparativo sobre los usos efectivos y los sentidos de los medios de comunicación indígenas y afroamericanos en América Latina. A partir de los conceptos de multivocalidad y multimodalidad repensamos y experimentamos con la metodología y la escritura etnográficas. Ambos conceptos tienen la potencialidad de incorporar las nociones de diferencia y jerarquía vinculadas a la idea de una pluralidad en permanente interacción. Efectivamente, el principal reto del proyecto y de la web MEDIOS INDÍGENAS es aprehender las diferencias y la heterogeneidad características de la comunicación indígena y afroamericana sin diluirlas en el momento de la escritura y la interpretación etnográficas.

Palabras clave: etnografía; medios de comunicación; amerindios; afroamericanos; hipertextualidad; multimodalidad; multivocalidad.

\section{[en] Hypertext, Multivocality and Multimodality for an Ethnography on Media: the Web MEDIOS INDIGENAS}

\begin{abstract}
In this paper we reflect on hypertextual and transmedia ethnography in methodological, ethi$\mathrm{cal}$ and theoretical terms. Our reflection revolves around the INDIGENOUS MEDIA website, which is part of a collective and comparative research project on the effective uses and meanings of indigenous and African-American media in Latin America. Based on the concepts of multivocality and multimodality, we rethink and experiment with ethnographic methodology and writing. Both concepts have the potential to incorporate the notions of difference and hierarchy linked to the idea of a plurality in permanent interaction. Indeed, the main challenge of this project and the INDIGENOUS MEDIA website is to grasp the differences and heterogeneity characteristic of indigenous and African-American communication without dissolving them in ethnographic writing and interpretation.
\end{abstract}

Keywords: ethnography; media; Amerindians; African Americans; hypertextuality; multimodality; multivocality.

Sumario: 1. Introducción. 2. El valor de la hipertextualidad: desencializar y conectar. 3. Estructura de la web: la heterogeneidad como eje metodológico y analítico. 4. Multimodalidad: aprehender la pluralidad. 5. Multivocalidad: conceptualizar la multiplicidad. 6. Conclusiones. 7. Referencias.

\footnotetext{
Departamento de Antropología Social, Universidad de Barcelona. orobitg@ub.edu
}

2 Departamento de Antropología Social, Universidad de Barcelona. rocanals@ub.edu 
Cómo citar: Orobitg, Gemma y Roger Canals. 2020. "Hipertexto, multivocalidad y multimodalidad para una etnografía sobre los medios de comunicación: la web MEDIOS INDÍGENAS". Revista Española de Antropología Americana 50: 215-227.

\section{Introducción}

En este texto reflexionamos sobre las potencialidades y los efectos del hipertexto digital para el desarrollo de la investigación antropológica. Concretamente, consideramos cómo el dispositivo hipertextual contribuye a reevaluar, ampliar e intensificar la investigación etnográfica, la interpretación de las observaciones, la elaboración de los conceptos, los modos de escritura o representación, así como la difusión de los resultados. Adicionalmente, desde un punto de vista teórico, abordamos el dispositivo hipertextual y transmedial como una herramienta para repensar recursivamente algunos de los conceptos y debates fundamentales de la disciplina antropológica, como la noción de "resultado", la cuestión de la escritura y la autoridad etnográfica o el clásico debate acerca del "retorno" del conocimiento antropológico a los sujetos que han participado en su proceso de formación.

Nuestra reflexión se basa en la experiencia de la web MEDIOS INDÍGENAS ${ }^{3}$, pensada y diseñada por un equipo de 16 investigadores ${ }^{4}$ reunidos para realizar un estudio etnográfico comparativo sobre los usos de las tecnologías de comunicación por parte de colectivos indígenas y afroamericanos de América del Sur, haciendo hincapié en el impacto social, cultural y político de dichas tecnologías.

Seguidamente, presentamos la experiencia del diseño y del funcionamiento de la página web en cuatro apartados. En el primer de ellos, argumentamos sobre el valor de la hipertextualidad para hacer etnografía. En el segundo apartado describimos la estructura de la web mostrando cómo las decisiones en términos de diseño y programación responden a criterios vinculados con la propia investigación. En el tercer y cuarto apartado ejemplificamos el uso y el alcance de la multimodalidad y de la multivocalidad para una etnografía sobre los medios de comunicación indígenas y afroamericanos.

Para facilitar la lectura de este artículo sería útil un recorrido previo por la web o una consulta simultánea.

\section{El valor de la hipertextualidad: desencializar y conectar}

Desde el inicio de la investigación ${ }^{5}$, nuestro planteamiento fue trabajar en colaboración con los comunicadores y colectivos de comunicación indígena. En este sentido,

\footnotetext{
http://mediosindigenas.ub.edu/.

http://mediosindigenas.ub.edu/proyecto/\#investigadores.

La investigación sobre medios de comunicación indígenas y afroamericanos se inició en el año 2016 con el proyecto $\mathrm{I}+\mathrm{D}+\mathrm{i}$, Pueblos indígenas, medios de comunicación y significados del conflicto en América Latina. Un estudio de antropología (HAR2015-65442-P). Esta investigación inicial de tres años tiene su continuidad en un nuevo proyecto $\mathrm{I}+\mathrm{D}+\mathrm{i}$, Comunicación indigenas y patrimonio cultural en América Latina: conservación, revitalización, creatividad (PGC2018-095841-B-I00).
} 
la página web MEDIOS INDÍGENAS se diseñó como una herramienta para optimizar esta dimensión colaborativa. Los diferentes bloques se pensaron como opciones diversas para esta participación que el proyecto ofrece no sólo a los comunicadores y colectivos indígenas, sino también a académicos y expertos. Inicialmente, optamos también por el desarrollo de una investigación plural, es decir, que diera cuenta de la heterogeneidad de la comunicación indígena y afroamericana, y desvelara la dinámica de las relaciones dentro de esta pluralidad.

Con este fin, hemos ido incorporado a la web, por un lado, vínculos que descubren la variedad de medios y experiencias de la comunicación indígena y afroamericana en América Latina - es decir, la heterogeneidad de sus "paisajes mediáticos"6Por otro lado, también, hemos querido representar en la web la pluralidad ideológica -defensa de las culturas, resistencia, colonización, descolonización, revitalización, creatividad o modernización, entre otras- que activa esta comunicación. Para asegurar esta investigación colaborativa y plural, la web incluye diferentes registros y estrategias de comunicación: textos, fotografías, videos, cuñas de audio y mapas interactivos.

En este sentido, la construcción de la web responde a lo que Manuel Gutiérrez Estévez (2005) ha presentado como una "hipertextualidad dura o fuerte". En otras palabras, la convergencia en el espacio de la web de un conglomerado de plataformas y géneros digitales de comunicación indígena y afroamericana, junto con otras que hacen referencia a ella busca evitar una narración única y sin fisuras, para exhibir, al contrario, un "uso no jerarquizado de lógicas diversas, pasando de la analogía, a la topología, a la homofonía, o a la genealogía" (Gutiérrez 2005: 101-102). Esta forma de hipertextualidad, si bien difumina las especificidades teóricas y analíticas de la investigación dentro del entramado de vínculos, nodos y redes que se ofrecen al lector para aproximarse a la comunicación indígena -lo que en algunos círculos académicos y activistas resulta cuestionable-, configura lo que Roland Barthes definió como un "texto plural". La interpretación de este texto plural, plantea este autor, más allá de desvelar un sentido único, hace emerger "el plural del que está hecho" (Barthes 1970: 11). Veamos la definición de Barthes de "texto plural" - o el "texto ideal" - que se adecua a nuestra etnografía sobre los medios de comunicación indígenas y afroamericanos a través de la web MEDIOS INDÍGENAS:

"En este texto ideal, las redes son múltiples e interaccionan entre ellas sin que ninguna pueda llegar a eclipsar a las demás; este texto es una galaxia de significantes y no una estructura de significados; no tiene un inicio; es reversible; se accede a él a través de múltiples entradas sin que ninguna de ellas pueda erigirse como la principal; los códigos que movilizan son infinitos; son indecidibles (el sentido no está nunca sometido a un principio de decisión, sino al juego del azar); los sistemas de sentido pueden apoderarse de este texto absolutamente plural, pero al tener como medida lo infinito del lenguaje, su número no se cierra nunca. [...] Todo esto implica que para el texto plural no puede haber estructura narrativa, gramática o lógica de la narración; si unas y otras se dejan a veces entrever, es en la medida en

Utilizamos la definición de "paisaje mediático" (mediascapes) propuesta por Arjun Appadurai, (1996: 299). Los medios de comunicación construyen comunidades sobre la base de flujos de relaciones que van más allá de lo "oficialmente" o previamente establecido. Los paisajes mediáticos implican la participación de las personas en la construcción del mundo en el que viven. 
que estamos frente a textos incompletamente plurales, textos en los que el plural es más o menos parsimonioso" (Barthes 1970: 12).

Esta caracterización coincide en gran medida con la noción computacional de hipertexto o hipermedia ${ }^{7}$, un texto no secuencial que está formado por bloques de texto e información audiovisual conectados entre ellos de tal manera que permiten al lector diferentes posibilidades de lectura (Landow 2006: 2-3).

Efectivamente, como plantea Gutiérrez Estévez (2005), el hipertexto, como un texto plural, viene a resolver los dilemas de la etnografía, que al trabajar sobre otras culturas -es decir sobre otros lenguajes que atesoran formas propias de conceptualizar el mundo- constata sus limitaciones lingüísticas y conceptuales para expresar las nociones indígenas. La yuxtaposición en la web de bloques temáticos generados por distintos sujetos, a veces antagónicos, vinculados con la comunicación indígena y afroamericana, permite superar las afirmaciones asertivas y nomológicas para, en su lugar, reproducir las complejidades que descubrimos en el trabajo de campo (Gutiérrez 2005: 101). Por un lado, el diseño de la web, como ya hemos avanzado, permite presentar la pluralidad de medios, actores, voces, ideologías y experiencias de la comunicación, sin subsumir las unas a las otras. Por otro lado, a través de la hipertextualidad hemos podido reproducir la opacidad conceptual y las asociaciones de sentidos inesperadas que experimentamos durante el trabajo de campo, en particular, las formas originales y genuinas de pensar los usos de las tecnologías de la información y el valor de la comunicación por parte de los comunicadores y las audiencias indígenas y afroamericanas.

Sin embargo, la pertinencia del hipertexto para organizar la etnografía sobre la comunicación indígena y afroamericana va más allá de la optimización de las estrategias de descripción e interpretación etnográficas que acabamos de presentar. Como sugiere Gutiérrez Estévez (2005: 101), la hipertextualidad actualiza el relato de forma diferente en cada lectura, como sucede en la tradición oral. En este sentido, su construcción narrativa presenta similitudes con la transmisión de la mitología en las culturas indígenas, donde es corriente que el etnógrafo reúna múltiples versiones -a veces tantas como interlocutores- de una misma historia mítica. En esta misma línea, la manera en la que el hipertexto construye la textualidad recupera la noción del bricoleur, que Claude Lévi-Strauss (1962: 30) estableció como el principio lógico del pensamiento mítico indígena -también presente, aunque residualmente, en el pensamiento occidental-, que elabora nuevos significados a partir de la recombinación de fragmentos de elementos ya existentes. Efectivamente, como en el hacer mítico, apunta también Gutiérrez Estévez (2005: 114), la escritura etnográfica hipertextual permite construir un relato diferente cada vez que el lector navega por un texto abarrotado de hipervínculos. En resumen, la hipertextualidad nos acerca a la lógica narrativa indígena, así como a su idea sobre el valor de uso que adquiere el relato en cada una de sus versiones. Uno no puede dejar de pensar aquí en el célebre ensayo de Lévi-Strauss (1974) acerca de la estructura de los mitos donde el autor argumentaba que el lenguaje computacional -por aquel entonces, aún naciente- presentaba estrechas analogías con las formas mitológicas más elementales ${ }^{8}$.

Tal como sugiere George P. Landow, utilizamos la noción hipertexto, incluyendo la de hipermedia: "Hipermedia extiende simplemente la noción del texto en el hipertexto, incluyendo información visual, sonido, animación y otras formas de datos" (Landow 2006: 3).

8 Ambos se fundamentaban, argumenta Lévi-Strauss (1974) sobre un sistema binario dinámico y no secuencial 
El paradigma del hipertexto presenta también sugerentes analogías con el mundo afroamericano, es decir, con el conjunto de culturas que surgieron en América Latina a raíz del encuentro, las más de las veces violento, entre poblaciones indígenas, europeas y afrodescendientes. Las sociedades que se formaron han sido a menudo descritas como "mestizas" o "sincréticas", unos términos discutibles desde el punto de vista teórico pero que dejan entrever su carácter esencialmente aglutinante, plural y heterogéneo, siempre cambiante. Las religiones afroamericanas (Santería, Umbanda, Espiritismo) son un buen ejemplo de la dimensión hipertextual del mundo afroamericano: en dichas prácticas interaccionan una pluralidad de agentes muy diversos ("dioses", "espíritus de los antepasados", "creyentes") mediante un conjunto de prácticas rituales que involucran textos, música, imágenes, cuerpos y objetos rituales. El panteón espiritual sobre el que se fundamentan reúne un sinfín de "espíritus" de diversa procedencia y naturaleza. En resumen, se trata de expresiones culturales radicalmente polifónicas y multimediales (Canals 2018) que desafían cualquier concepción esencialista y unívoca de la cultura.

En términos generales, las continuidades y analogías que hemos sugerido entre el entramado hipertextual, el pensamiento indígena y la formación de la cultura afroamericana apuntan hacia desesencializar la establecida oposición entre la presunta coherencia del pensamiento indígena y el carácter explícitamente "híbrido" e inventivo de la cultura afrolatinoamericana. Nuestra investigación constata cómo las sociedades indígenas y afroamericanas constituyen realidades plurales y heterogéneas, también en cuanto al uso de los medios de comunicación. Dichas sociedades hacen unos usos originales y creativos de las tecnologías de la comunicación que no solamente nos permite afirmar su coetaneidad en el accionar del mundo (Wolf 1982) y su contribución a la modernidad (Pitarch y Orobitg 2012), sino que además nos invita a pensar desde otros ángulos sobre qué es un medio de comunicación y qué significa comunicar.

\section{Estructura de la web: la heterogeneidad como eje metodológico y analítico}

La web MEDIOS INDÍGENAS está estructurada en tres apartados en constante proceso de construcción ${ }^{9}$ en función de las dinámicas de la investigación, así como de la participación y las colaboraciones de los colectivos de comunicadores y académicos. Se accede a cada apartado tanto desde la parte superior de la página web como desde el scroll de la página de inicio, un desplazamiento vertical que permite una visualización rápida de los bloques de la web y de sus contenidos.

El primer bloque, cuyo título es "Proyecto", describe la investigación, presenta a los investigadores y permite el acceso a las publicaciones y audiovisuales produci-

organizado a partir de relaciones de complementariedad y oposición entre términos mínimos, lo que en su teoría mitológica llamó "mitemas". La fuerza del argumento de Lévi-Strauss reside en el hecho de ver en la tecnología más "avanzada" y "moderna", un dispositivo para entender uno de los recursos más ancestrales que la Humanidad ha utilizado para dar sentido al mundo, y viceversa. Esta tesis tiene evidentes repercusiones a nivel teórico y político: declaradamente anti-evolucionista, apunta a la idea de que la Humanidad "siempre ha pensado igual", y problematiza, sin diluir por completo, la distinción entre el pensamiento científico y el pensamiento salvaje.

9 Se ha utilizado de base para la programación de la web, el sistema de gestión de contenidos Wordpress que permite introducir sencillamente las actualizaciones de la web cuando son necesarias. 
dos. Desde este bloque de la web se facilita el contacto individual, a través de correo electrónico, con cada uno de los investigadores. La comunicación con el proyecto se posibilita a partir de la rúbrica "Contacto" que aparece al final del scroll de inicio e, igualmente, en el extremo superior derecho de la página web. Su objetivo es alentar a que, después de cada recorrido por la web, se envíen comentarios, sugerencias o aportaciones que amplíen la pluralidad del hipertexto.

El segundo bloque, "Medios indígenas en acción", se compone de un mapa interactivo cuyo objetivo es la visualización del alcance de los medios de comunicación indígena y afroamericana en América Latina. Las entradas en el mapa aparecen, indistintamente, por grupo étnico, área geográfica, área cultural, organización indígena, redes de comunicadores y otras. Constatamos que esta variación de criterios en las entradas del mapa responde a las especificidades de cada caso tratado. En efecto, las políticas de comunicación de cada país, el desarrollo de proyectos estatales de transferencia tecnológica a los pueblos indígenas, así como las posibles actuaciones de ONGs apoyando la formación e implementación de medios indígenas, crean una diversidad de paisajes mediáticos que se visibilizan en el mapa a través de esta variabilidad de los criterios que dan título a las entradas. Nuestra idea inicial era aplicar un criterio generalizable a toda la comunicación indígena, pero tuvimos que desistir de ello, y aceptar que las variaciones en los criterios reproducen la heterogeneidad de las experiencias en la comunicación que constatan nuestras investigaciones.

Cada uno de estos puntos en el mapa tiene asociada una ficha que contiene una relación de los medios de comunicación -listado y vínculos- y una síntesis del estado de la comunicación indígena y afroamericana en cada ubicación teniendo en cuenta distintos factores (históricos, culturales y políticos). El texto de la ficha proporciona el contexto al listado de los medios. Igualmente, este texto ofrece un análisis del "paisaje mediático" que se configura en la lista de los vínculos a los medios de comunicación indígena que se reúnen en cada caso. Por otro lado, cada ficha incluye el nombre de sus autores y el contacto. Se trata de ampliar y completar el panorama con nuevas aportaciones, manteniendo la autoría (ideología) de lo expuesto.

Es posible obtener distintas visualizaciones del mapa combinando, por el momento, dos categorías: medios (televisión, radio, prensa, prensa online, blogs, YouTube, Facebook, Twitter, cine y video indígena) y países. Desde nuestra perspectiva, distintas relecturas del mapa deben ampliar y afinar las categorías que describen, conectan y confrontan las experiencias de la comunicación. Nuestro objetivo es ampliar las categorías definitorias de cada entrada para producir visualizaciones inéditas de la comunicación indígena.

El tercer bloque, "Comunicación e investigación", reúne posts de noticias relacionadas con la comunicación indígena. Se trata de noticias aparecidas en medios indígenas, en medios de comunicación alternativos, plataformas de organismos gubernamentales, internacionales y no-gubernamentales, así como en los mass media. En este apartado vinculamos las noticias, que contienen temáticas y enfoques diversos de la comunicación indígena, con los post que redactamos a partir de nuestras investigaciones etnográficas y publicamos también en este bloque. El objetivo es vincular y conectar los resultados del proyecto con esta pluralidad de actores e ideologías. Por este motivo, cada post tiene asignadas unas categorías temáticas y unas etiquetas por países que posibilitan relacionarlos entre sí.

A lo largo de la investigación, este bloque se ha revelado como un archivo de datos sobre la comunicación indígena. Cada post se elabora a partir de una noticia 
aparecida en distintos medios, y sus principales contenidos son: 1) el medio en que se ha publicado, 2) la fecha de consulta, 3) texto e imágenes de la noticia, 4) enlace (link) a la fuente original. Así, se ha dado el caso que la fuente original desaparece, pero el contenido de la noticia queda preservado en la web MEDIOS INDÍGENAS. Por lo demás, cada post incluye, asimismo, la posibilidad de enviar comentarios, que son validados por el equipo del proyecto para su publicación.

En términos de diseño e imagen, nuestro mayor reto ha sido poder expresar en la propia conceptualización y estética de la web el carácter horizontal, contemporáneo y profundamente ecléctico del uso de los medios de comunicación en contextos indígenas y afroamericanos. Para ello decidimos combinar diferentes técnicas de representación (texto, vídeo, fotografía, audio) y crear una plataforma que visualmente se alejara de ciertos clichés que todavía reproducen una visión selvática, primitivista y algo infantil de dichas comunidades. Asumimos, en este sentido, un planteamiento acorde con la antropología multimodal, como justificamos en el siguiente apartado.

\section{Multimodalidad: aprehender la pluralidad}

El concepto de multimodalidad se refiere a una antropología experimental, pública y participativa que hace uso de una pluralidad de medios, recursos y técnicas para el trabajo de campo, así como para la representación y difusión de los resultados de la investigación (Collins et al. 2017). La multimodalidad se concibe como un cuestionamiento del principio de univocidad que ha servido de base a gran parte de la antropología clásica y al pensamiento occidental. Así, la multimodalidad invita a pensar los procesos de investigación en términos plurales, como redes de colaboración y participación que dan lugar a una variedad de conocimientos, prácticas y artefactos (libros, artículos, películas, páginas web...). En este sentido, se discute la noción de "autoría" y la tradicional separación entre autor y receptor.

Otra de las principales premisas del giro multimodal es que, en el marco de la revolución digital en la que vivimos, la investigación de campo debe combinar textos, fotografías, vídeo o recursos digitales, utilizando una metodología que reproduzca los usos que hacen nuestros interlocutores en campo de estos diversos formatos y lenguajes. Este es precisamente uno de los principios que ha guiado nuestra investigación etnográfica, así como el planteamiento y diseño de la página web. Durante el trabajo de campo, los y las investigadoras de este proyecto se han centrado en analizar los media "a través" de los medios de comunicación, haciendo uso, entre otros, de la cámara de vídeo, fotografía y, sobre todo, llevando a cabo una etnografía online a través de las redes sociales. La etnografía online ha difuminado las clásicas distinciones entre el "aquí" y el "allá" -entre el lugar de residencia del antropólogo y el lugar donde se realiza el trabajo de campo- generando una conversación permanente, y dando lugar a una etnografía ya no sólo multisituada sino multivocal.

Esta pluralidad de estrategias de investigación se traduce en la necesidad de adoptar a su vez una multiplicidad de modos de representación o difusión de los resultados de investigación. La antropología multimodal es, en este sentido, una antropología transmedial, que se expresa mediante texto, cine, fotografía, teatro, proyectos expositivos, recursos digitales o a través de iniciativas de intervención social. El conjunto de todos estos resultados constituye una suerte de crisol o constelación donde cada producción complementa críticamente a las otras (Canals 2018). En efecto, la web 
reúne textos de naturaleza diversa (artículos académicos, posters, noticias, comunicados, comentarios de los lectores, programas de las reuniones del grupo de investigación, anuncios de festivales de cine, cursos y becas para fomentar la comunicación indígena, etc.), así como mapas interactivos, documentos audiovisuales, sonoros y fotográficos. La web a su vez debe entenderse como parte de una constelación más amplia de resultados que abarca también libros, artículos, presentaciones en congresos o seminarios y proyectos de divulgación e intervención social.

Todo este trabajo plural y colaborativo que hemos estado llevando a cabo, y que la web MEDIOS INDÍGENAS visibiliza y expande, enlaza a su vez con otro de los puntos principales del giro multimodal, que es la problematización de la noción tradicional de resultado de la investigación. Así, de lo que se trata no es de mostrar investigaciones presuntamente acabadas y definitivas sino de dar valor y visibilidad al conjunto de tentativas, ensayos y aproximaciones que definen el propio avance de la investigación. Observamos aquí un esfuerzo reflexivo y crítico para sacar a la luz la naturaleza necesariamente colaborativa, experimental y no lineal de toda investigación. En palabras de Bruno Latour (1991), el objetivo es "despurificar" el artefacto antropológico. La investigación se entiende como un dispositivo inacabado e inacabable de producción de conocimientos necesariamente incompletos y problemáticos, que se expresan mediante una pluralidad de formatos y que involucran una amplia red de agentes sociales. La web MEDIOS INDÍGENAS ejemplifica esta reevaluación de la noción de resultado de varias maneras.

En el bloque 1, por ejemplo, introducimos los resúmenes de las reuniones de trabajo con el fin de poner en evidencia cómo el conocimiento emerge de una práctica discursiva plural -lo que Ingold (1996) llamó "a theory in the making"-. El mapa del bloque 2, por su parte, muestra los puntos geográficos donde se están realizando los trabajos de campo, y visibiliza los links de los comunicadores e instituciones donde esta investigación se desarrolla. Toda esta información se refiere a pesquisas en curso y, por lo tanto, es permanentemente susceptible de ser cambiada o modificada. Finalmente, los posts que componen el tercer bloque de la web ("Comunicación e Investigación”) se presentan como textos-comentarios de eventos contemporáneos. Su objetivo no es aportar interpretaciones o explicaciones definitivas sino más bien apuntar hacia posibles líneas de reflexión y de trabajo. Esta sección es una suerte de collage de informaciones que va actualizándose regularmente y que, en su conjunto, da fe de la vitalidad y complejidad del uso de los medios de comunicación entre los grupos indígenas y afroamericanos.

Finalmente, la antropología multimodal se compromete con los principios de una antropología pública e implicada, que afronta los debates contemporáneos y que se esfuerza en producir un conocimiento abierto y gratuito que llegue a un máximo de sectores de la sociedad, contribuyendo así, en la medida de lo posible, a la mejora de las condiciones de existencia de los más desfavorecidos. Es por esta razón que en nuestro proyecto hemos realizado un esfuerzo para publicar nuestros resultados en acceso abierto. Por otro lado, la página web no rehúye ni los debates, a veces agrios, que emergen en el seno de las comunidades indígenas y afroamericanas en torno a los medios de comunicación, ni los conflictos que estas sociedades mantienen con diferentes agentes políticos o económicos. En el fondo, no se trata únicamente de hacer una web sobre los medios indígenas y afroamericanos, sino de reivindicar, a través del estudio de una serie de casos específicos, una mirada mucho más abierta y crítica sobre los avances tecnológicos y los medios de comunicación que tome en 
consideración un conjunto de realidades locales presuntamente "periféricas" cuyas voces, a menudo, quedan excluidas de los debates sobre el futuro del planeta (Augé 2017: 17).

\section{Multivocalidad: conceptualizar la multiplicidad}

La multivocalidad se refiere a una composición que es resultado de la convergencia de una multiplicidad de voces. Es una noción propia de las teorías del discurso que reúne tres conceptos: polifonía, dialogismo y heteroglosia (Robinson 2011) ${ }^{10}$. Atendiendo a esta complejidad del concepto, constatamos que la multivocalidad ha sido objeto de un uso parcial en antropología. En efecto, la crítica posmoderna a la autoridad etnográfica incorporó, de los tres, únicamente la noción de dialogismo a su reflexión sobre el método y la escritura antropológica (Tedlock 1998, 2001). Por su parte, el uso que hizo la antropología visual de multivocalidad se circunscribe a su acepción de polifonía (Marcus 1995; Pink 2009). Probablemente, el uso más complejo para la antropología de la noción de multivocalidad, lo desarrolla Tania Stolze Lima (2011) en su análisis de la obra de Pierre Clastres. Lima vincula esta noción no sólo a la pluralidad de voces sino, sobre todo, a los regímenes de diferencia-también en cada cultura- $\mathrm{y}$ a la distribución del poder.

Así pues, trabajar sobre la noción de multivocalidad implica incorporar a la etnografía: 1) la polifonía o la multiplicidad de voces que convergen en una experiencia social, 2) el dialogismo o la multiplicidad de perspectivas ideológicas, a veces incompatibles entre sí, que interaccionan sin subordinarse unas a las otras, puesto que, como sucede en las interacciones cotidianas, todo se construye en relación con lo dicho o expresado por otros, y 3 ) la heteroglosia o la multiplicidad de estilos sociales del habla que interaccionan activando el potencial creativo del lenguaje. "Incluso dentro de una sola perspectiva, siempre hay múltiples voces y perspectivas, porque el lenguaje que se utiliza ha sido tomado de otros" (Robinson 2011).

En particular, para la antropología, el uso de la noción de multivocalidad abunda en el cuestionamiento de las dicotomías canónicas que estructuran nuestro pensamiento occidental: Nosotros-Otros, Civilizado-Salvaje, Cultura-Naturaleza, Humano-Animal, Natural-Sobrenatural, por citar alguna ellas. El peso argumentativo de estas dicotomías es tan fuerte, que incluso cuando algunos antropólogos han querido cuestionarlas para, por ejemplo, dar cuenta de la especificidad de las lógicas del pensamiento amerindio, no han podido hacerlo sin recurrir a ellas. Efectivamente, como sostiene Tania Stolze Lima, "[...] al mismo tiempo en que afirmamos que estas sociedades indígenas no oponen naturaleza y cultura, no separan ni diferencian a los humanos de los no-humanos, estamos paradójicamente obligados a movilizar estas mismas oposiciones iniciales en la pintura de su retrato" (Lima 2011: 616). Para evitar esta contradicción argumentativa resulta interesante el razonamiento de Lima (2011: 617) que parte de un esquema conceptual según el cual las diferencias entre los entes sociales no están al servicio de la delimitación de sus identidades sino que resulta ser la condición necesaria para la comunicación entre

10 Sus antecedentes son dos estudios de Mikhail Bakhtin sobre la obra de Fiódor Dostoievski, Problems of Dostoievsky's Poetics (1999) y Dialogical imagination (1981). 
ellos. En otras palabras, lo social estaría codificado por una "miríada de distancias" entre los entes sociales, de manera que "las disyunciones son afirmadas como tales: y las conjunciones son un medio privilegiado para afirmar otras disyunciones" (Lima 2011: 620). Esta idea de la diferencia como aquello irreductible y esencial para las relaciones sociales -que Lima identifica a partir de varios ejemplos amerindios- coincide plenamente con la noción de multivocalidad tal como la hemos utilizado para la construcción de la web.

Cada uno de los tres bloques de la web MEDIOS INDIGENAS resulta del desarrollo de estrategias diversas para fundamentar la multivocalidad de la etnografía. Reunir la pluralidad de voces, ideologías e idiomas sociales que configuran la experiencia de la comunicación indígena y afroamericana, necesita del uso de lenguajes y formatos diversos. Es precisamente esta multimodalidad la que consolida la multivocalidad de nuestra etnografía sobre la comunicación indígena y afroamericana. La yuxtaposición en la web de distintos formatos y metodologías colaborativas contribuye a no reducir las diferencias mediales a una síntesis unívoca (por ejemplo, en un texto), al mismo tiempo que facilita una presentación no jerarquizada de las diferentes formas de representación, aunque evidenciando las jerarquías que de hecho funcionan socialmente.

En el primer bloque, "Proyecto", la publicación de textos académicos y otros destinados a un público general -ya sea en el formato de artículo de opinión o de entrevista- cuestiona la idea del carácter local de la comunicación indígena y la de su mera "reproducción" de la comunicación no-indígena. A partir de nuestras experiencias de campo argumentamos cómo los pueblos indígenas modernizan los medios de comunicación otorgándoles unas características muy genuinas: la "relacionalidad" o puesta en relación de lo comunitario a lo planetario y la "experimentación social" de las potenciales transformaciones tanto de la sociedad indígena, como, en general, de la Humanidad. Estos dos conceptos nos permiten guiar el análisis comparativo sin difuminar la heterogeneidad que caracteriza las experiencias de la comunicación indígena y afroamericana tal como las hemos observado (Orobitg et al. 2021).

Con este mismo objetivo se ha experimentado con varios formatos de producción audiovisual que presentamos en este mismo bloque: 1) expositivo: audiovisual corporativo descriptivo del proyecto MEDIOS INDÍGENAS; 2) recopilatorio de voces: serie documental televisiva de tres episodios, La comunicación indígena. Un derecho en construcción, realizada a partir de las autograbaciones de los comunicadores y de entrevistas a académicos expertos en comunicación comunitaria; 3) dialógico y reflexivo: documental etnográfico Wási, en el que el antropólogo Sebastián Gómez Ruíz y el cineasta arhuaco Amado Villafaña conversan y reflexionan sobre lo que significa ver y comunicar desde la perspectiva indígena. Estos distintos formatos audiovisuales aseguran la polifonía, el dialogismo y la yuxtaposición de distintos lenguajes para el análisis de la comunicación indígena.

Estos aspectos, que definen la multivocalidad, se despliegan también en los otros dos bloques de la web. En el segundo, que contiene el mapa de los paisajes mediáticos indígenas, la multivocalidad está, aparentemente, menos presente que en los otros dos bloques. De hecho, se trata de una multivocalidad programática. A través del mapa interactivo, se proporcionan diferentes herramientas que permiten activarla. Esto es, el listado exhaustivo de los medios de comunicación para cada caso, la posibilidad de agrupar el conjunto de casos estudiados en relación con un solo medio de comunicación y, finalmente, el texto que contextualiza el listado de medios 
para cada caso de estudio se presenta como un preludio, una invitación a un diálogo complejo y matizado sobre la actualidad de los medios indígenas. El tercer bloque es el más representativo de la multivocalidad del proyecto. La elaboración de los posts sigue este criterio. También el listado de categorías temáticas en la parte inferior derecha de este bloque. Si abrimos cualquier de estas categorías que relacionan temáticamente los posts, observamos que el conjunto de noticias dibuja este enfoque polifónico, dialógico y heteroglósico que caracteriza nuestra investigación.

Dentro de este entramado de la web, la antropología participa como una voz más que entra en conversación con las voces de comunicadores indígenas y otros agentes sin aspirar a una posición dominante y rehuyendo la tentación académica de resumir o simplificar la pluralidad de voces o discursos en unos principios simples y pretendidamente omniexplicativos.

\section{Conclusiones}

En este artículo hemos discutido los cuestionamientos teóricos, éticos y metodológicos que subyacen en el diseño y elaboración de la web MEDIOS INDÍGENAS. Hemos argumentado también que el trabajo con y a través de esta plataforma transmedia constituye un buen punto de partida para reevaluar recursivamente algunos de los principios fundamentales de la antropología.

Nuestro argumento se ha fundamentado en los conceptos de "hipertextualidad", "multimodalidad" y "multivocalidad". Aunque distintos, estos tres conceptos se encuentran íntimamente entrelazados. En efecto, todos ellos se relacionan, por un lado, con la noción de pluralidad (ya sea una pluralidad de métodos, de resultados o de voces) y, por el otro, con la necesidad de problematizar las relaciones de autoridad y autoría que, de forma más o menos explícita, han cimentado gran parte de la antropología clásica. Así, hemos mostrado cómo la etnografía hipertextual desafía la idea del texto como un relato lineal, cerrado e internamente coherente. Nos movemos más bien en una concepción intensiva del texto: éste se concibe como un espacio abierto, sin inicio ni final -es decir, como una fuente potencial de producción de significantes-. El texto es un lugar de paso, un punto de encuentro donde se entrecruzan una pluralidad de discursos, actores y recursos mediáticos. Multimodalidad y multivocalidad, por su parte, son términos que dan cuenta de un mismo impulso en la antropología contemporánea para integrar y pensar críticamente los conceptos de diferencia y heterogeneidad tanto al nivel metodológico como conceptual. Mientras que la noción de multimodalidad subraya la necesidad de integrar una pluralidad de métodos y formas de representación en la antropología (textos, imágenes, sonidos...), la multivocalidad reafirma su compromiso con la variedad de posicionamientos políticos e ideológicos que se entrecruzan en el proceso de investigación. La web MEDIOS INDÍGENAS se define como un dispositivo abierto, permanentemente actualizado, donde, mediante la combinación de diferentes estrategias de escritura, se entrecruzan una pluralidad irreductible de discursos.

Concebimos la web como un dispositivo que emerge desde el propio tejido social que constituye el paisaje mediático indígena y afroamericano. Así, la web amplía y extiende este campo, participando en él y reivindicándose como un actor más en el proceso de redefinición de qué es un medio de comunicación y de qué significa hoy ser indígena o afroamericano. 
Desde un punto de vista político y conceptual, el mayor reto de la web MEDIOS INDÍGENAS ha sido preservar las diferencias y la heterogeneidad características de la comunicación indígena y afroamericana contemporánea. Se trataba, en definitiva, de ahondar en el análisis de esta pluralidad como aspecto definitorio de la comunicación indígena y afroamericana evitando la tentación de sintetizarla en unos pocos principios abstractos y fijos. Nuestra intención era dar cuenta de la multiplicidad de actores, recursos mediáticos, lenguajes e ideologías imbricados en los procesos de comunicación indígena y afroamericana, y entender nuestra propia voz y posicionamiento como un nodo más dentro de una interminable red de relaciones y mediaciones, siempre en movimiento. Nuestro objetivo ha sido que todas estas voces, heterogéneas, pero necesariamente superpuestas entre sí, cristalizaran en la página web, respetando sus especificidades, y poniendo al descubierto las posibles divergencias y fisuras que entre ellas pudiera haber. No diluir la pluralidad de experiencias e ideologías de la comunicación indígena y afroamericana ha sido el principio que ha regido nuestro trabajo como investigadores e investigadoras. Es también en base a esta convicción que continuaremos nuestra investigación acerca de cómo, a través de los medios de comunicación, los humanos imaginan y redefinen las relaciones que mantienen entre sí y con su entorno.

\section{Referencias}

Appadurai, Arjun. 1996. Modernity at Large. Cultural Dimensions of Globalization. Minnesota: University of Minnesota Press.

Augé, Marc. 2017. L'avenir des terriens. Fin de la préhistoire de l'humanité comme société planétaire. París: Albin Michel.

Bakhtin, Mikhail. 1999 (1929). Problems of Dostoevsky’s Poetics. Minneapolis: University of Minnesota Press.

—. 1981 (1975). The Dialogic Imagination. Four Essays. Austin: University of Texas Press.

Barthes, Roland. 1970. S/Z. París: Éditions du Seuil.

Canals, Roger. 2018. «Studying Multi-Modal Religions: Migration and Mediation in the Cult of María Lionza (Venezuela, Barcelona, Internet)». Visual Anthropology Review 34 (2): 124-135.

Collins, Samuel Gerald, Matthew Durington y Harjant Gill. 2017. «Multimodality: An Invitation». American Anthropologist 119 (1): 142-153.

Gutiérrez Estévez, Manuel. 2005. «Hypertexte et écriture ethnographique». Diogène 211: 100-116.

Ingold, Tim, ed. 1996. Key Debates in Anthropology. Londres: Routledge.

Landow, George P. 2006 (1992). Hypertext 3.0: Critical Theory and New Media in an Era of Globalization. Baltimore: The Johns Hopkins University Press.

Latour, Bruno. 1991. Nous n'avons jamais été modernes. París: La Découverte.

Lévi-Strauss, Claude. 1962. La pensée sauvage. París: Librairie Plon.

—. 1974. Anthropologie Structurale. París: Librairie Plon.

Lima, Tania Stolze. 2011.«Por uma cartografia do poder e da diferença nas cosmopolíticas ameríndias». Revista de Antropologia (Universidade de Sao Paulo) 54 (2): 601-646.

Marcus, George. 1995. «The Modernist Sensibility in Recent Ethnographic Writing and the Cinematic Metaphor of Montage», en Fields of Vision: Essays in Film Studies, Visu- 
al Anthropology and Photography, Leslie Devereaux y Roger Hillman, eds., pp. 35-55. Berkeley: University of California Press.

Orobitg, Gemma, Mònica Martínez Mauri, Roger Canals, Gemma Celigueta, Francisco M. Gil García, Sebastián Gómez Ruiz, Gabriel Izard, Julián López García, Óscar Muñoz Morán, Beatriz Pérez Galán y Pedro Pitarch. 2021. «Los medios indígenas en América Latina: usos, sentidos y cartografías de una experiencia plural». Revista de Historia. (Universidad de Costa Rica) 83 (en prensa, enero-junio 2021).

Pink, Sarah. 2009. Doing Visual Ethnography: Images, Media and Representation. Londres: SAGE Publications.

Pitarch, Pedro y Gemma Orobitg, eds. 2012. Modernidades indígenas. Madrid: Iberoamericana/Vervuert.

Robinson, Andrew. 2011. «Bakhtin: Dialogism, Polyphony and Heteroglossia». Ceascefire. https://ceasefiremagazine.co.uk/in-theory-bakhtin-1/.

Tedlock, Denis. 1998. «Preguntas concernientes a la antropología dialógica», en El surgimiento de la Antropología Posmoderna, Carlos Reynoso, ed., pp. 275-288. Barcelona: Gedisa.

—. 2001. «El surgimiento de la antropología dialógica en las Américas», en Motivos de la Antropología Americanista. Indagaciones en la diferencia, Miguel León-Portilla, coord., pp. 460-505. México: Fondo de Cultura Económica.

Wolf, Eric. 1982. Europe and the People without History. Berkeley: University of California Press. 